\title{
Multiobjective Optimization of Carbon Fiber-Reinforced Plastic Composite Bumper Based on Adaptive Genetic Algorithm
}

\author{
Dawei Gao $\mathbb{D}^{1},{ }^{1}$ Haotian Liang, ${ }^{1}$ Guijie Shi $\mathbb{D},{ }^{2}$ and Liqin Cao $^{3}$ \\ ${ }^{1}$ School of Mechanical Engineering, University of Shanghai for Science and Technology, Shanghai 200093, China \\ ${ }^{2}$ State Key Laboratory of Ocean Engineering, School of Naval Architecture, Ocean and Civil Engineering, \\ China Strategy Institute of Ocean Equipment Engineering, Shanghai Jiao Tong University, Shanghai 200240, China \\ ${ }^{3}$ College of Environment and Chemical Engineering, Yanshan University, Qinhuangdao 066004, China \\ Correspondence should be addressed to Guijie Shi; sgj2004@sjtu.edu.cn
}

Received 19 April 2019; Revised 3 October 2019; Accepted 30 October 2019; Published 15 November 2019

Academic Editor: Francesco Aymerich

Copyright (C) 2019 Dawei Gao et al. This is an open access article distributed under the Creative Commons Attribution License, which permits unrestricted use, distribution, and reproduction in any medium, provided the original work is properly cited.

\begin{abstract}
Genetic algorithm (GA) is a common optimization technique that has two fatal limitations: low convergence speed and premature convergence to the local optimum. As an effective method to solve these drawbacks, an adaptive genetic algorithm (AGA) considering adaptive crossover and mutation operators is proposed in this paper. Verified by two test functions, AGA shows higher convergence speed and stronger ability to search the global optimal solutions than GA. To meet the crashworthiness and lightweight demands of automotive bumper design, CFRP material is employed in the bumper beam instead of traditional aluminum. Then, a multiobjective optimization procedure incorporating AGA and the Kriging surrogate model is developed to find the optimal stacking angle sequence of CFRP. Compared with the conventional aluminum bumper, the optimized CFRP bumper exhibits better crashworthiness and achieves $43.19 \%$ weight reduction.
\end{abstract}

\section{Introduction}

People nowadays have the increasing awareness of energy conservation and emission reduction and focus more on passive safety performance of cars in collisions. Therefore, the crashworthiness and lightweight design of automobile body structure are regarded as one of the most important parts of vehicle design. Substantial researchers devoted themselves to conduct research studies on improvement of crashworthiness and reduction weight of vehicles. To sum up, there are mainly three ways to achieve these goals: adjustment of material usage, improvement of manufacturing processes, and optimization design of vehicle structure. It is proved that the combination of material adjustment and optimized design of body structure is the most effective way to improve the crashworthiness and realize lightweight $[1,2]$.

In the latest research studies, carbon fiber-reinforced plastic (CFRP) composites have been increasingly utilized instead of conventional metallic materials in the automotive industry due to their advantageous properties like high strength, high stiffness, lightweight, and excellent energy absorption [3-8]. Kiran et al. proposed the method of using composite instead of metallic materials in automobile chassis and analyzed the static structure of equivalent stress and displacement of composite structural parts [9]. Kim et al. designed carbon fiber-reinforced composites and hybrid fiberglass-reinforced composite hood by finite element analysis and proved that composite hood had better performance in crashworthiness and weight reduction than traditional steel and aluminum hood [4].

As the main load-bearing and energy-absorbing part in the low-speed collision of the car, the bumper system plays a vital role in protecting other parts of the car and the safety of the occupants [4, 10-12]. Therefore, it is of great significance to make the optimization design of the car bumper. Combining genetic algorithm, linear perturbation eigenvalue analysis method, and static RIKS analysis technique, Kim et al. designed a carbon fiber-reinforced composite automotive lower arm, which is characterized by twice the stiffness and buckling strength of the steel lower arm and 
$50 \%$ decline in weight [13]. To find out the suitable material of bumper beam, Kim et al. used hybrid glass/carbon fiberreinforced composite that had 33\% lighter weight and better crashworthiness to replace conventional glass mat-reinforced thermoplastic (GMT) [13].

Recently, the integration of finite element analysis and optimization algorithms has been an advanced way to improve the crashworthiness and lightweight performance of the automotive body structure [14-17]. Fang et al. formed a complete optimized design flow that can be utilized as references by introducing DOE (design of experiment), surrogate model, and multiobjective optimization analysis methods into the crashworthiness and lightweight design of body parts $[18,19]$. The selection of optimization algorithm will dominate the quality and accuracy of the result, so a variety of intelligent algorithms are proposed by many researchers $[11,20]$; i.e., Sun et al. presented a novel optimization algorithm named ICGA (integer-coded genetic algorithm) and applied it on the configurational optimization of multicell topologies [21]. It can be concluded that increasing intelligent algorithms are applied to multiobjective optimization design of the vehicle, such as particle swarm optimization (PSO), genetic algorithms, and simulated annealing algorithms. The genetic algorithm is one of the most common algorithms, but its limitations, i.e., low convergence speed and premature convergence to the local optimum, are often reported in research studies $[22,23]$. Therefore, the improvement of GA is necessary and significant.

In this study, design optimization of the carbon fiberreinforced composite bumper is carried out with the combination of finite element analysis, the Kriging surrogate model, and multiobjective optimization. The carbon fiber stacking angle sequence is determined to be the optimal design variables, with the purpose of improving the crashworthiness and lightweight performance of CFRP composite bumper. For the multiobjective optimization problem, the selection of the algorithm is the most critical, so an adaptive genetic algorithm (AGA) is presented to generate the best possible design of the carbon fiber stacking angle sequence.

\section{Adaptive Genetic Algorithm}

2.1. Limitations and Improvement of GA. Genetic algorithm (GA) is widely employed to search the global optimal solution in optimization problems; however, it has some defects in solving complicated optimization problem [24], such as the premature convergence to the local optimum and much time consuming. The crossover probability $P_{c}$ and mutation probability $P_{\mathrm{m}}$ greatly determine the quality of solutions and the convergence speed of GA [25]. The moderately large values of $P_{c}$ promote the extensive recombination of schemata, while small values of $P_{\mathrm{m}}$ are necessary to prevent the disruption of the solutions. Instead of fixed values of $P_{\mathrm{c}}$ and $P_{\mathrm{m}}$, AGA utilizes the population information in each iteration and adaptively adjusts the $P_{\mathrm{c}}$ and $P_{\mathrm{m}}$ to maintain the population diversity as well as to sustain the convergence capacity. And the roulette wheel selection method is employed as the selection operator.
It is essential to identify whether the GA is converging to an optimum. The difference in the average and maximum fitness values of the population [26], $F_{\max }-F_{\text {avg }}$, is used to be a yardstick for detecting the convergence of GA. And when GA converges to a local optimum, the value of $F_{\text {max }}-F_{\text {avg }}$ decreases. Therefore, the values of $P_{\mathrm{c}}$ and $P_{\mathrm{m}}$ are supposed to be varied adaptively depending on the value of $F_{\max }-F_{\text {avg }}$ to prevent premature convergence of the GA to local optimum. In addition, to preserve the "good" solutions of every populations, lower values of $P_{\mathrm{c}}$ and $P_{\mathrm{m}}$ should be set for high fitness solutions and higher values of $P_{\mathrm{c}}$ and $P_{\mathrm{m}}$ should be set for low fitness solutions $[27,28]$. While the high fitness solutions aid in the convergence of the GA, the low fitness solutions prevent the GA from getting stuck at a local optimum. So the values of $P_{\mathrm{m}}$ should depend on the fitness values $F$ of the solution too. Similarly, the values of $P_{\mathrm{m}}$ should also depend on the fitness values $F$ l of both the parent solutions. The closer the $F(F \prime)$ is to $F_{\max }$, the smaller the $P_{\mathrm{c}}\left(P_{\mathrm{m}}\right)$ should be. From the above, the adaptive value of $P_{\mathrm{c}}$ and $P_{\mathrm{m}}$ can be expressed as follows:

$$
\begin{aligned}
& P_{\mathrm{c}}= \begin{cases}\frac{P_{\mathrm{cl}}\left(F_{\mathrm{max}}-F^{\prime}\right)}{F_{\max }-F_{\mathrm{avg}}}, & F^{\prime} \geq F_{\mathrm{avg}}, \\
P_{\mathrm{cl}}, & F^{\prime}<F_{\mathrm{avg}},\end{cases} \\
& P_{\mathrm{m}}= \begin{cases}\frac{P_{\mathrm{m} 1}\left(F_{\max }-F\right)}{F_{\max }-F_{\mathrm{avg}}}, & F \geq F_{\mathrm{avg}}, \\
P_{\mathrm{m} 1}, & F<F_{\mathrm{avg}},\end{cases}
\end{aligned}
$$

where $P_{\mathrm{cl}}$ and $P_{\mathrm{m} 1}$ are less than 1.0 to constrain $P_{\mathrm{c}}$ and $P_{\mathrm{m}}$ to the range $(0.0-1.0), F$ is the individual fitness, $F^{\prime}$ is larger of the fitness values of the solutions to be crossed, and $F_{\text {avg }}$ and $F_{\max }$ is the average and maximum fitness values of the population, respectively.

However, the adapting crossover probability $P_{\mathrm{c}}$ and mutation probability $P_{\mathrm{m}}$ defined by equations (1) and (2) have a drawback: if $F\left(F^{\prime}\right)=F_{\text {max }}$, the values of $P_{c}$ and $P_{\mathrm{m}}$ are zero that will lead to premature convergence to the local optimum. As an effective method to overcome this drawback, improved equations to calculate $P_{\mathrm{c}}$ and $P_{\mathrm{m}}$ are proposed in this paper; they can be corrected as

$$
\begin{aligned}
& P_{\mathrm{c}}= \begin{cases}\frac{P_{\mathrm{c} 1}\left(F_{\mathrm{max}}-F^{\prime}\right)}{F_{\mathrm{max}}-F_{\mathrm{avg}}}+P_{\mathrm{c} 2}, & F^{\prime} \geq F_{\mathrm{avg}}, \\
P_{\mathrm{c} 1}+P_{\mathrm{c} 2}, & F^{\prime}<F_{\mathrm{avg}},\end{cases} \\
& P_{\mathrm{m}}= \begin{cases}\frac{P_{\mathrm{m} 1}\left(F_{\max }-F\right)}{F_{\max }-F_{\mathrm{avg}}}+P_{\mathrm{m} 2}, & F \geq F_{\mathrm{avg}}, \\
P_{\mathrm{m} 1}+P_{\mathrm{m} 2}, & F<F_{\mathrm{avg}},\end{cases}
\end{aligned}
$$

where $P_{\mathrm{c} 2}$ and $P_{\mathrm{m} 2}$ are the added parameters that can avoid the condition of $P_{\mathrm{c}}=P_{\mathrm{m}}=0$, which will avoid premature convergence to the local optimum. The process of adaptive algorithm is depicted in Figure 1. 


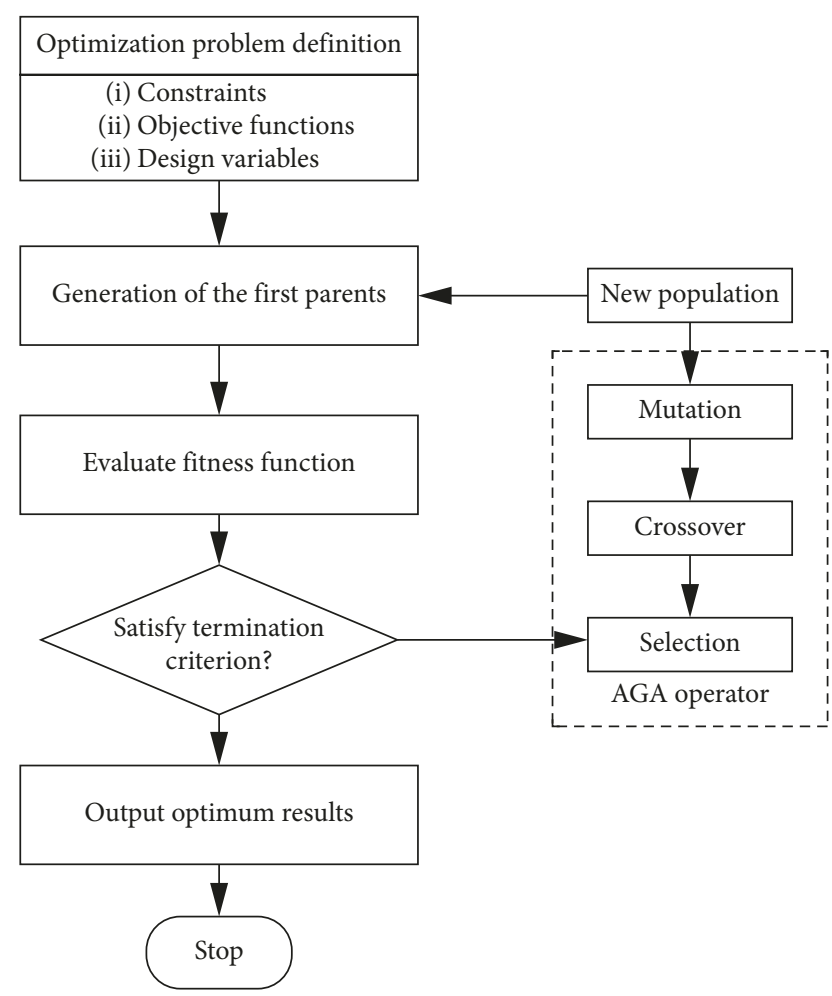

FIGURE 1: Flowchart of adaptive genetic algorithm.

2.2. Performance Test of Adaptive Genetic Algorithm. In this study, two typical test functions are employed to test and evaluate the adaptive genetic algorithm and genetic algorithm and thus verify their optimization performance.

\subsubsection{Schaffer Function.}

$$
Z=0.5-\frac{\left(\sin \sqrt{x^{2}+y^{2}}\right)^{2}-0.5}{\left(1+0.001\left(x^{2}+y^{2}\right)\right)^{2}} .
$$

The function is a multipeak function with multiple local maxima, which is mainly utilized to test the optimal accuracy of the algorithm [29]. The function can be expressed as equation (4), and then, the optimal problem for the test is constructed as follows:

$$
\begin{cases}\operatorname{Max} & Z(x, y) \\ \text { s.t. } & x, y \in[-4,4] .\end{cases}
$$

The global maximum of Schaffer function is $f(0,0)=1$, and there are countless local maxima at the value of 0.99028 around the global maximum. The graphical representation of function and contour line is shown in Figure 2.

\subsubsection{Rosenbrock Function.}

$$
f(x)=\sum_{i=1}^{n-1}\left(100\left(x_{i}^{2}-x_{i-1}\right)^{2}+\left(x_{i}-1\right)^{2}\right) .
$$

This function is a nonconvex function, which is widely used as a performance test function for optimization algorithms [30]. The function can be expressed as equation (4), and then, the optimal problem for the test is constructed as follows:

$$
\begin{cases}\text { Min } & f(x, y) \\ \text { s.t. } & x_{i} \in[-10,10] .\end{cases}
$$

The global minimum is inside a long, narrow, parabolicshaped flat valley. To find the valley while trivial and to converge to the global minimum are also difficult. The graphical representation of function is shown in Figure 3.

The genetic algorithm and adaptive genetic algorithm are tested by the Schaffer function, respectively, for comparison. To provide a fair comparison and test the robustness of the AGA and GA, the population size is set at 10, 15, and 20, respectively, and the maximum number of iterations for two algorithms is fixed at 100. Referring to the previous research [26], the values of $P_{\mathrm{c}}$ and $P_{\mathrm{m}}$ can be set as 1 and 0.5 for GA, while the values of $P_{\mathrm{c} 1}$ and $P_{\mathrm{m} 1}$ are also set as 1 and 0.5 for AGA. And the values of $P_{\mathrm{c} 2}$ and $P_{\mathrm{m} 2}$ are 0.5 and 0.01 to constrain the $P_{\mathrm{c}}$ and $P_{\mathrm{m}}$ to the best range [31]. Each test function is tested 30 times in MATLAB, and then, the optimal, worst, and average values of fitness are obtained in AGA and GA. The performance comparison between AGA and GA under different test functions is shown in Table 1, and the fitness curves are plotted in Figures 4 and 5 .

From Table 1 and Figures 4 and 5, the performance of AGA and GA can be concluded as follows:

(1) In terms of Schaffer function, both AGA and GA can jump to the local optimal solution and reach the global optimal solution at value of 1 , but the convergence speed of AGA is faster than GA

(2) For Rosenbrock function, the ability of searching global optimal solutions of AGA is better than GA; however, the convergence speed of AGA and GA is close

All in all, compared with the GA, the novel AGA proposed in this paper improves in both convergence speed and the ability to search global optimal solution.

\section{Finite Element Model}

In the whole process of a car frontal collision, the deformation of the car mainly concentrated in the front cabin while the deformation of the components behind a-pillar is small or almost no deformation occurs. Therefore, the finite element model of the body-in-white car is built as a reduced model, which uses a particle to replace the inessential components behind a-pillar. The size of the mesh is vital to the accuracy of CAE [32]; therefore, the element size of $5 \times 5 \mathrm{~mm}$ is determined to be sufficient for the front cabin, because this part has a great influence on crashworthiness, and $10 \times 10 \mathrm{~mm}$ is determined to the other parts. After preprocessing in Hypermesh software, the FE model is modeled by quadrilateral shell elements and the total number of elements is 226503, in which the triangular elements only account for $3.8 \%$, and it is shown in Figure 6.

Nonlinear finite element Ls-Dyna is utilized to simulate the crash behavior of automobile in this study. In the initial 


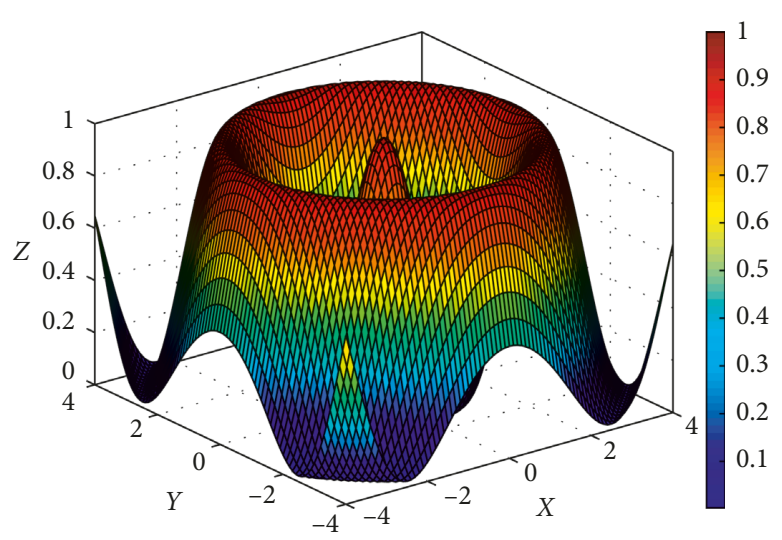

(a)

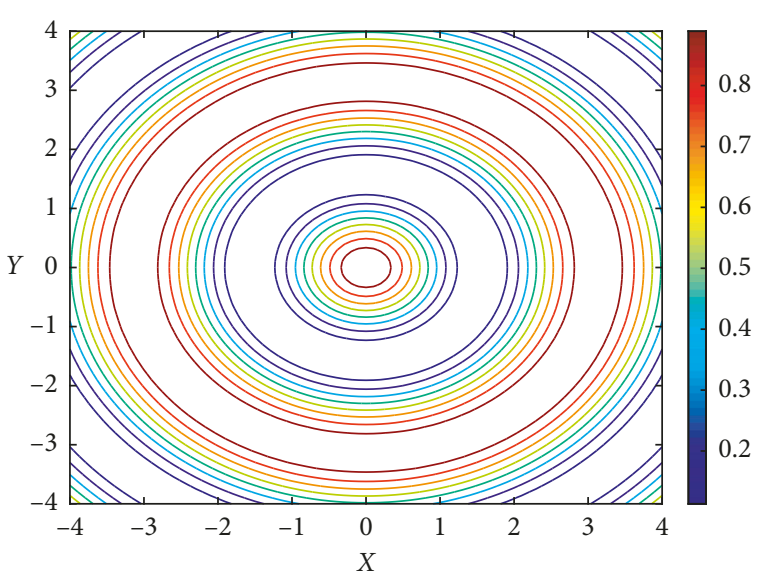

(b)

Figure 2: Graphics and contour line of Schaffer function: (a) graphics; (b) contour line.

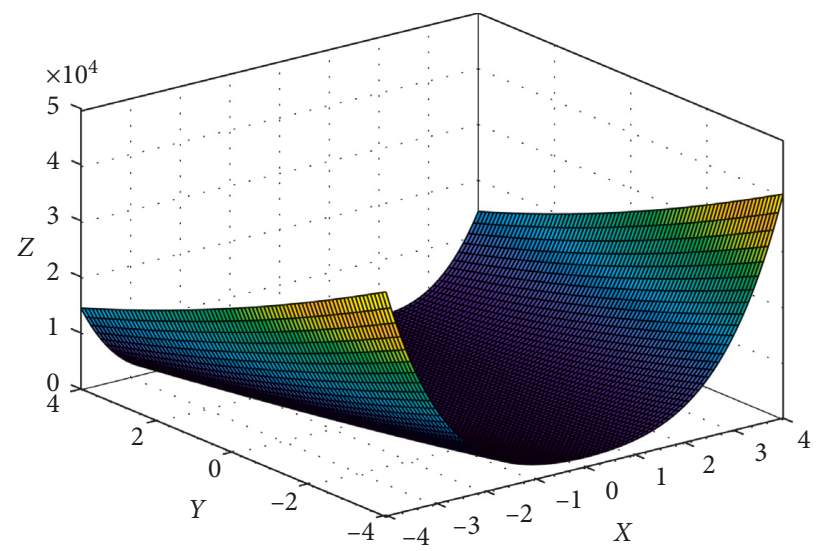

FIgURE 3: Graphics and contour line of Rosenbrock function.

TABle 1: Comparison of algorithm performance.

\begin{tabular}{|c|c|c|c|c|c|}
\hline Test function & Algorithm & Population size & Optimal solution & Worst solution & Average solution \\
\hline \multirow{7}{*}{ Schaffer function } & \multirow{3}{*}{ AGA } & 10 & 1 & 0.9982 & 0.9999 \\
\hline & & 20 & 1 & 1 & 1 \\
\hline & & 30 & 1 & 1 & 1 \\
\hline & \multirow{4}{*}{ GA } & 10 & 1 & 0.9801 & 0.9984 \\
\hline & & 20 & 1 & 0.9852 & 0.9991 \\
\hline & & 30 & 1 & 0.9993 & 0.9999 \\
\hline & & 10 & $6.4090 \times 10^{-4}$ & $6.4128 \times 10^{-4}$ & $6.4108 \times 10^{-4}$ \\
\hline \multirow{5}{*}{ Rosenbrock function } & \multirow{2}{*}{ AGA } & 20 & $6.4038 \times 10^{-7}$ & $8.4196 \times 10^{-7}$ & $7.2016 \times 10^{-7}$ \\
\hline & & 30 & $5.3694 \times 10^{-9}$ & $6.3283 \times 10^{-9}$ & $5.7953 \times 10^{-9}$ \\
\hline & \multirow{3}{*}{ GA } & 10 & $2.8100 \times 10^{-3}$ & $2.6120 \times 10^{-3}$ & $2.7800 \times 10^{-3}$ \\
\hline & & 20 & $4.7154 \times 10^{-5}$ & $6.2234 \times 10^{-5}$ & $5.2868 \times 10^{-5}$ \\
\hline & & 30 & $6.5108 \times 10^{-6}$ & $6.8200 \times 10^{-6}$ & $7.5864 \times 10^{-6}$ \\
\hline
\end{tabular}

model, aluminum is used as the material of the bumper beam. Based on the latest C-NCAP (China-New Car Assessment Program) [33], the collision velocity of the car is determined to be $50 \mathrm{~km} / \mathrm{h}$, the acceleration is $9.8 \mathrm{~m} / \mathrm{s}^{2}$, and the total time is $0.12 \mathrm{~s}$.

Then, the material of bumper beam is replaced by the GFRP composite. The bumper beam is the main frontal part of automotive structure during a frontal crash and is generally subjected to bending load. Therefore, stiffness of the initial bumper beam is supposed to be the same as the GFRP bumper beam [34], and the equal stiffness equation can be expressed as equation (9):

$$
E_{\mathrm{a}} I_{\mathrm{a}}=E_{\mathrm{l}} E_{1}
$$

where $I_{1}$ and $E_{1}$ are the inertia moment and elastic modulus of CFRP composite bumper, respectively, while the $I_{\mathrm{a}}$ and $E_{\mathrm{a}}$ 


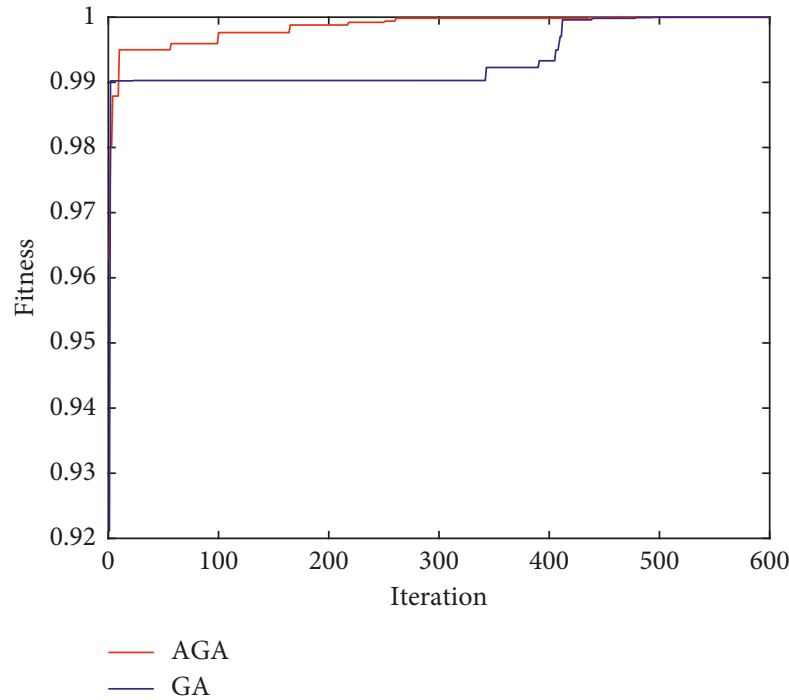

(a)

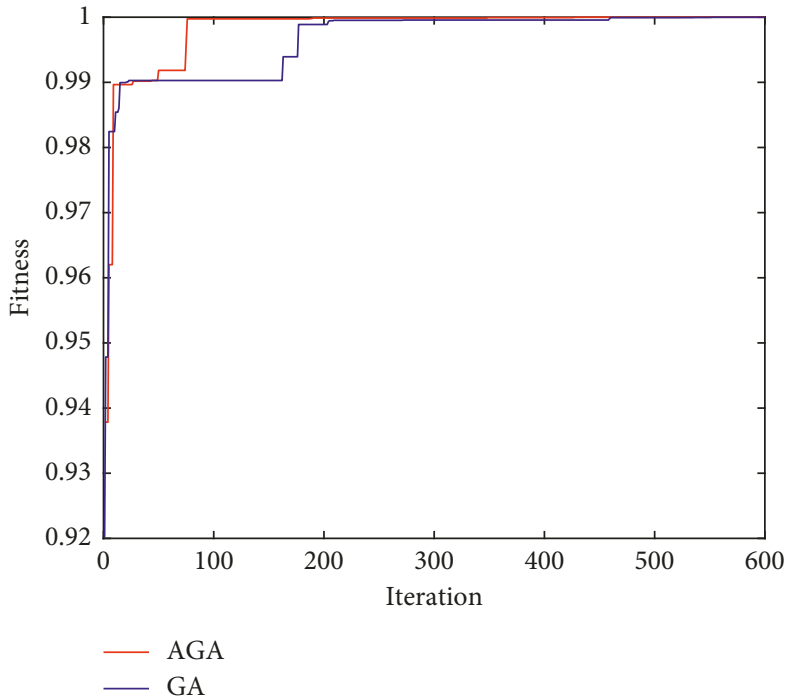

(b)

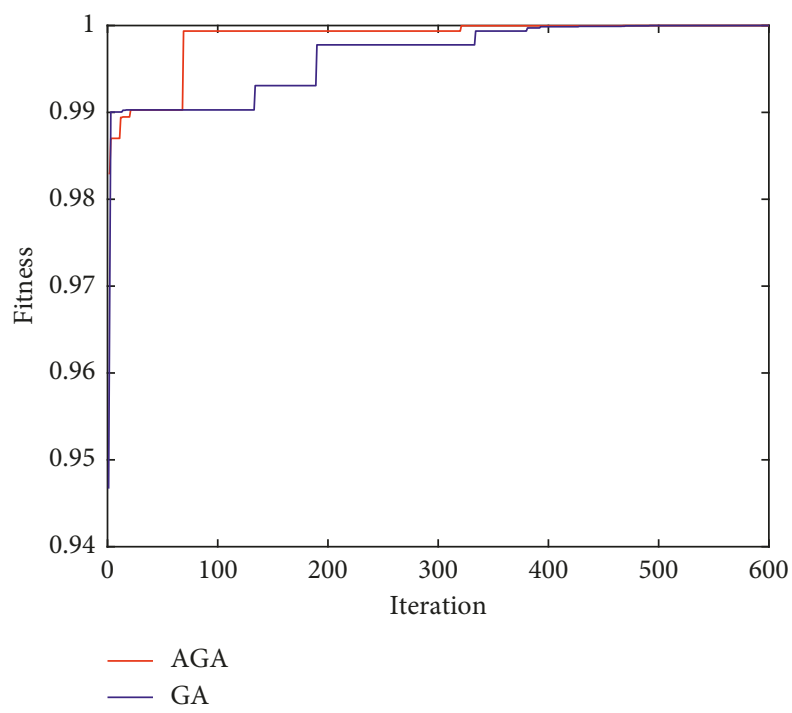

(c)

Figure 4: Fitness curves of GA and AGA under Schaffer function. (a) Fitness curve of Schaffer function at 10 population size. (b) Fitness curve of Schaffer function at 20 population size. (c) Fitness curve of Schaffer function at 30 population size.

are the inertia moment and elastic modulus of the aluminum bumper. And $I$ can be calculated by

$$
I=\frac{b h^{3}}{12} \text {. }
$$

Then, the thickness of CFRP composite bumper can be calculated by

$$
h_{1}=h_{\mathrm{a}} \sqrt[3]{\frac{E_{\mathrm{a}}}{E_{\mathrm{l}}}}
$$

where $h_{1}$ is the thickness of the CFRP composite bumper and $h_{\mathrm{a}}$ is the thickness of the aluminum bumper.

The thickness of the aluminum bumper beam is $1.80 \mathrm{~mm}$; therefore, the thickness of the CFRP bumper beam is $1.92 \mathrm{~mm}$ calculated by using equation (10). In Hypermesh software, the material model 54 (CFRP) is selected instead of aluminum in the bumper beam. The failure criteria of CFRP were introduced in the research [35]. After replacing the aluminum bumper beam by the CFRP bumper beam, the weight of the bumper beam is reduced from $3.790 \mathrm{~kg}$ to $2.153 \mathrm{~kg}$ that achieves $43.19 \%$ weight reduction. And the material properties of CFRP are listed in Table 2 [36].

\section{Multiobjective Optimization of CFRP Composite Bumper}

4.1. Definition of the Optimization Problem. The structures of composite have great flexibility in design, because they can be customized in different ways to meet specific design requirements. By selecting the best parameters such as fiber and matrix material, fiber orientation, or layer thickness, the fatigue strength of the laminated composite can be 


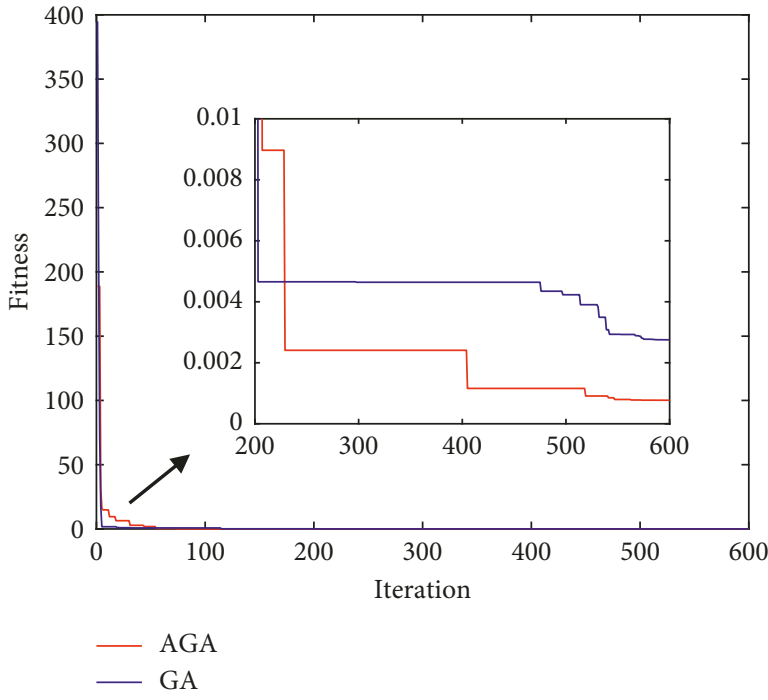

(a)

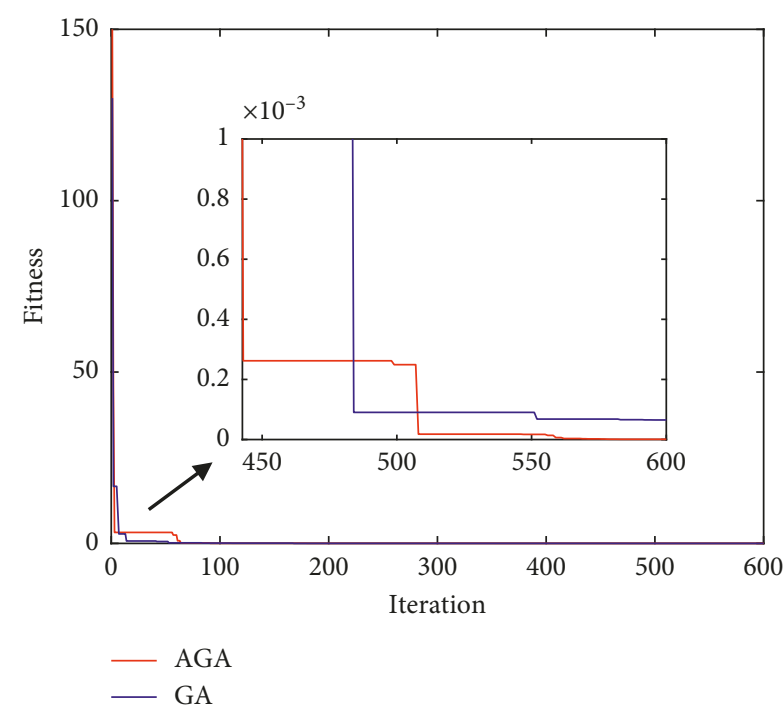

(b)

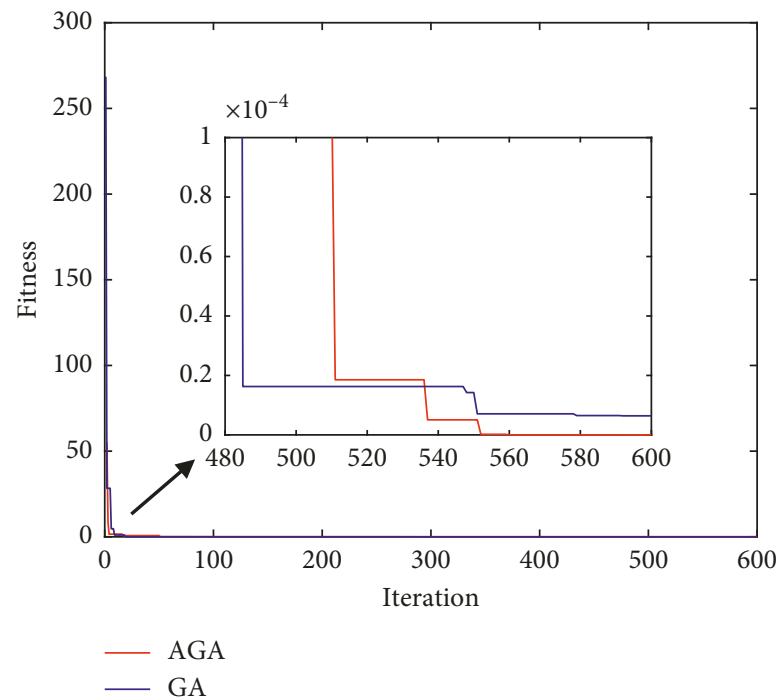

(c)

Figure 5: Fitness curves of GA and AGA under Rosenbrock function. (a) Fitness curve of Rosenbrock function at 10 population size. (b) Fitness curve of Rosenbrock function at 20 population size. (c) Fitness curve of Rosenbrock function at 30 population size.

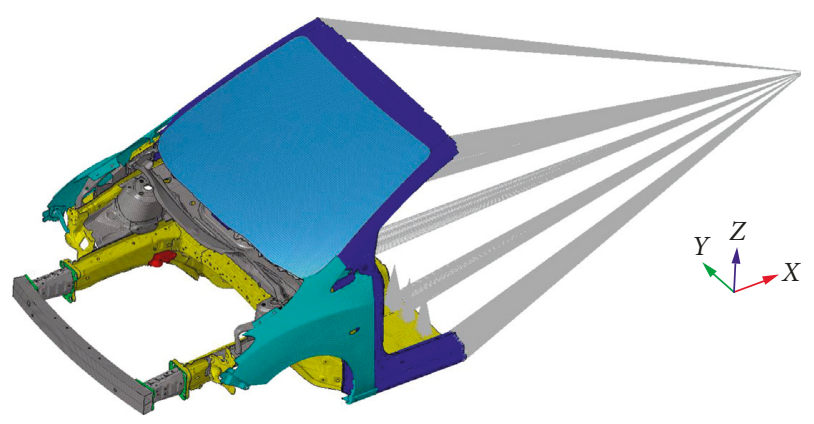

Figure 6: Finite element model.

significantly improved, thereby improving the structural properties [37, 38]. The CFRP composite studied in this research can be regarded as a multidirectional laminate plate composed by a single-layer plate that is laminated in different directions. The microstructure of CFRP can be shown in Figure 7.

The stiffness of CFRP is greatly affected by the different stacking angle sequences $[39,40]$; therefore, further optimization is carried out to find the optimal stacking angle sequence, with the purpose of improving the crashworthiness and reducing the quality of bumper.

4.1.1. Design Variables. The thickness of the bumper beam of the above model is $1.92 \mathrm{~mm}$, and CFRP laminates are designed as symmetric based on the center of the laminate and composed of ten layers in total, so the thickness of each ply is $0.192 \mathrm{~mm}$. Then, the stacking angle of each layer is determined to be the design variables; therefore, five independent design variables can be considered as $\left[x_{1} / x_{2} / x_{3} /\right.$ 
TABLE 2: Material properties of CFRP used in the FE model.

\begin{tabular}{lccc}
\hline & Property & Description & Value \\
\hline Mass & $\rho$ & Density & 1455 \\
& $X_{\mathrm{lt}}$ & Longitudinal tensile strength & 1409.9 \\
& $X_{\mathrm{lc}}$ & Transverse compressive strength & 764.1 \\
Strengths $(\mathrm{MPa})$ & $X_{\mathrm{tt}}$ & Longitudinal tensile strength & 42.5 \\
& $X_{\mathrm{tc}}$ & Transverse compressive strength & 121.6 \\
& $X_{\mathrm{lts}}$ & In-plane shear strength & 68.9 \\
& $E_{1}$ & Longitudinal elastic modulus & 129.3 \\
Elastic properties & $E_{2}=E_{3}$ & Transverse elastic modulus & 9.11 \\
& $G_{12}$ & Shear modulus & 5.44 \\
& $N u_{12}$ & Poisson's ratio & 0.3 \\
\hline
\end{tabular}

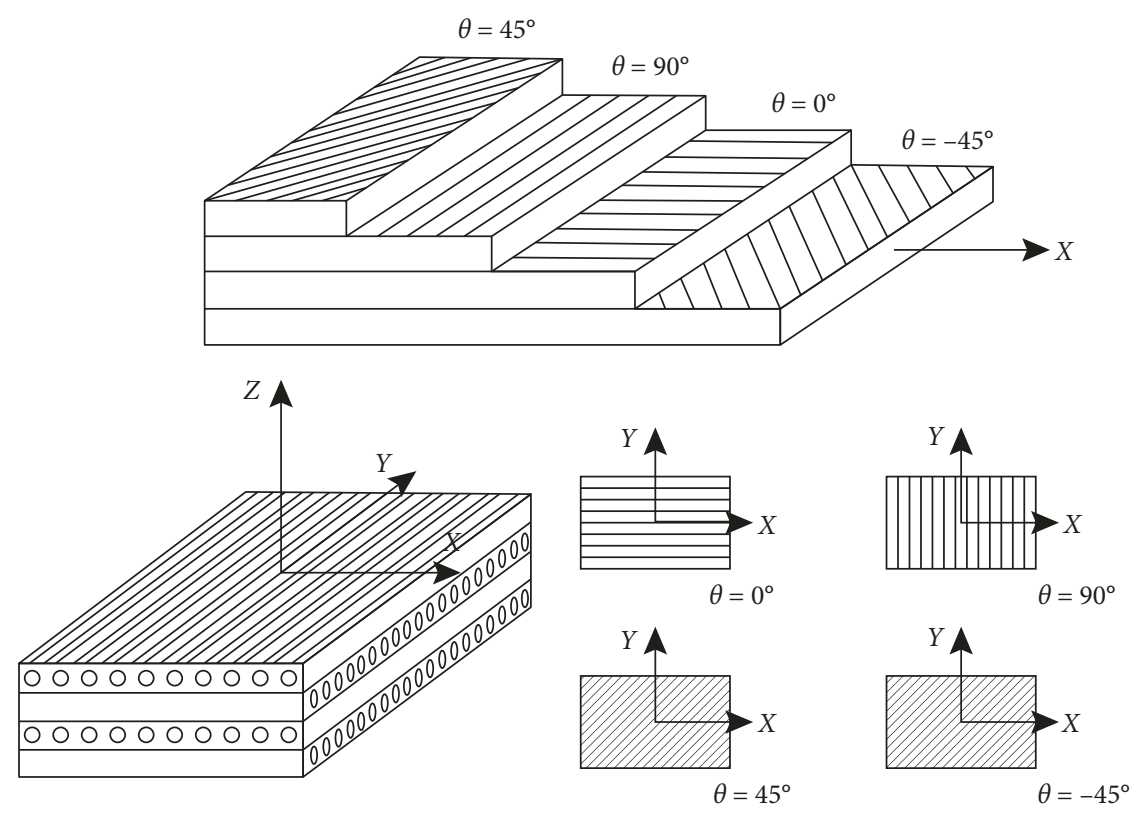

FIgURE 7: Microstructure of CFRP.

$\left.x_{4} / x_{5}\right]_{s}$, which represent the centrosymmetric stacking angle sequence of CFRP laminates. And the value of design variable $x$ can be taken as $[0 / \pm 45 / 90]$ based on the global coordinates. The schematic diagram of 10-plies CFRP based on the global coordinates is vividly depicted in Figure 8.

4.1.2. Constraints. The peak impact force $F$, the intrusion $L$, and the energy absorption $Q$ of bumper beam are considered to be the constraints of optimization design, and the values of them are supposed to be lower than those of initial aluminum model.

4.1.3. Objectives. According to C-NCAP, upward displacement automotive steering column $S_{1}$ and rearward displacement automotive steering column $S_{2}$ can be used to evaluate the crashworthiness and they are shown in Figure 9. And the purpose of optimization design is to minimize them.

The optimization problem can be defined mathematically as follows:

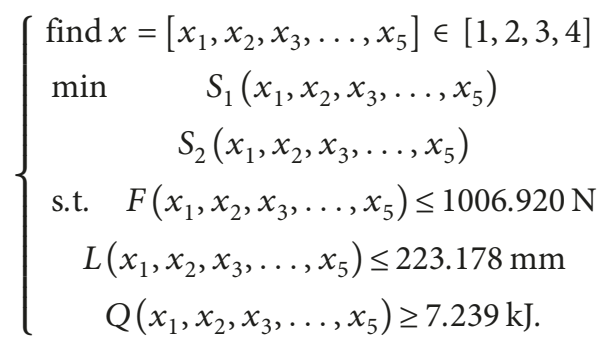

4.2. Kriging Model. Design optimization of crashworthiness and lightweight is a nonlinear problem that usually costs much time. In the optimization problem above, the objective function and constraint function are complicated nonlinear function. As an effective approach, the Kriging surrogate model is employed to represent multimodal and nonlinear functions in this paper [41-43]. It can be expressed as

$$
y(x)=f(x)+Z(x)
$$

where $f(x)$ is a constant approximate model, and it is similar to the polynomial response surface that provides 

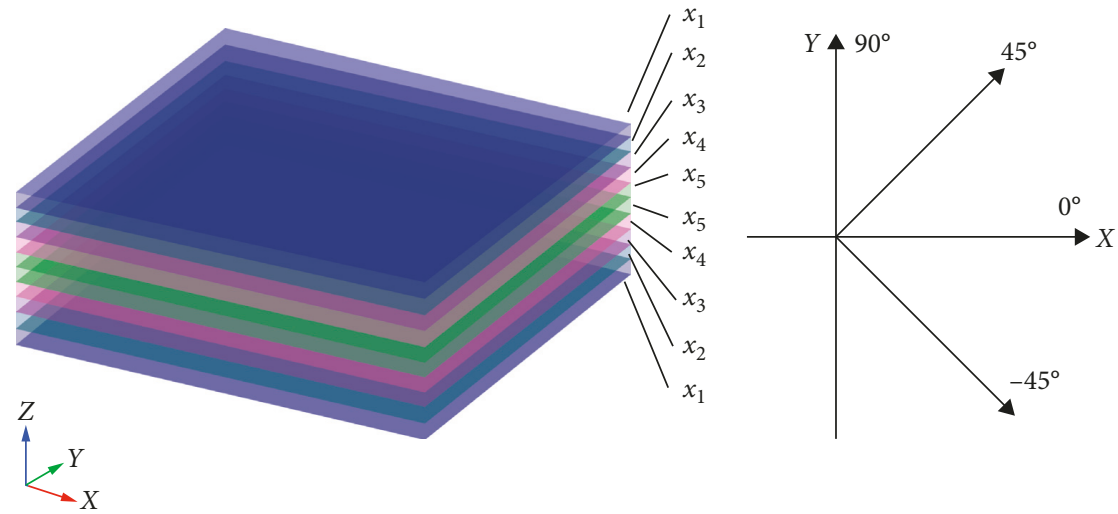

Figure 8: Schematic diagram of 10-plies CFRP based on the global coordinates.

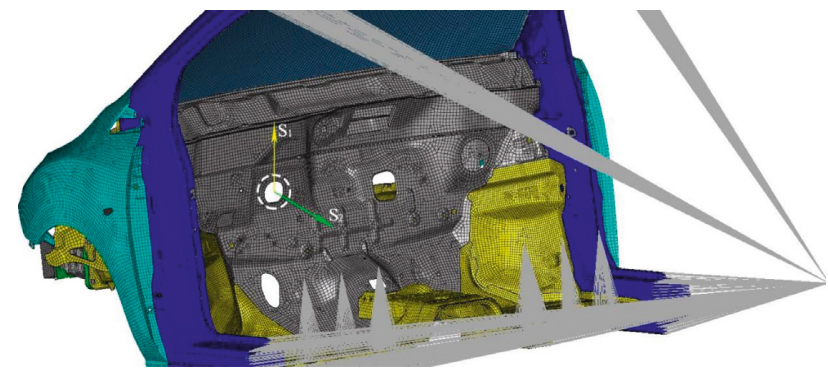

FIgURE 9: Diagram of $S_{1}$ and $S_{2}$ in the FE model.

design space for a global model and $Z(x)$ is a stochastic process with mean zero and variance $\sigma^{2}$ and it creates localized deviations to assist the Kriging model generating interpolation among sample points. The covariance matrix of $Z(x)$ is expressed as

$$
\operatorname{Cov}\left[Z\left(x^{i}\right), Z\left(x^{j}\right)\right]=\sigma^{2}\left[R\left(x^{i}, x^{j}\right)\right],
$$

where $R\left(x^{i}, x^{j}\right)$ is a correlation matrix of Gauss-Markov theorem.

In this study, the Kriging surrogate model is used to approximate $F, L, Q, S_{1}$, and $S_{2}$ functions for each case. Design of experiment (DOE), as a widely used technique to address how to select the minimum number of training points for mapping the entire design space properly, is the first step of surrogate modeling technique. The optimal Latin hypercube sampling (OLHS) [44] can efficiently generate uniformly distributed sampling points, so it is applied to generate 120 baseline designs. Then, the $F, L, Q, S_{1}$, and $S_{2}$ at these training points are calculated by Ls-Dyna software. All the calculation results are based on the global coordinate. Based on the simulation results, the Kriging models of the above optimal problem are constructed. To calculate easily, $1,2,3$, and 4 are substituted for $0^{\circ},-45^{\circ}, 45^{\circ}$, and $90^{\circ}$. The 120 baseline designs are shown in Table 3 .

The fitting accuracy of the Kriging surrogate model is crucial to the result of an optimal problem, and the $R^{2}$, RMAE (relative maximum absolute error), and RMSE (Root-mean-square error) are employed as the criterion to evaluate the accuracy of it [45]. They can be calculated by
Table 3: 120 baseline designs.

\begin{tabular}{ccccccccccc}
\hline $\mathrm{SN}$ & $x_{1}$ & $x_{2}$ & $x_{3}$ & $x_{4}$ & $x_{5}$ & $F(\mathrm{~N})$ & $\begin{array}{c}L \\
(\mathrm{~mm})\end{array}$ & $Q(\mathrm{~kJ})$ & $\begin{array}{c}S_{1} \\
(\mathrm{~mm})\end{array}$ & $\begin{array}{c}S_{2} \\
(\mathrm{~mm})\end{array}$ \\
\hline 1 & 1 & 1 & 3 & 2 & 3 & 1430.73 & 153.6 & 7.8585 & 75.04 & 81.26 \\
2 & 2 & 4 & 3 & 2 & 2 & 1375.26 & 136.96 & 7.8545 & 83.11 & 89.24 \\
3 & 1 & 2 & 1 & 1 & 2 & 1224 & 201.25 & 7.8031 & 71.39 & 95.76 \\
4 & 4 & 1 & 2 & 2 & 2 & 901.32 & 196.71 & 7.811 & 82.86 & 86.3 \\
5 & 3 & 1 & 4 & 3 & 1 & 1208.88 & 177.8 & 7.9812 & 77.56 & 87.56 \\
6 & 4 & 4 & 3 & 4 & 1 & 1405.52 & 174.02 & 7.8783 & 74.92 & 93.87 \\
7 & 4 & 3 & 4 & 3 & 3 & 1365.18 & 176.29 & 7.5458 & 77.06 & 97.02 \\
8 & 2 & 4 & 1 & 4 & 4 & 1153.42 & 143.01 & 7.9337 & 78.45 & 88.4 \\
9 & 4 & 3 & 4 & 2 & 3 & 997.11 & 202.76 & 7.7793 & 71.13 & 89.87 \\
10 & 4 & 3 & 4 & 4 & 3 & 1062.66 & 158.89 & 7.8189 & 84.87 & 87.35 \\
$\ldots$ & $\ldots$ & $\ldots$ & $\ldots$ & $\ldots$ & $\ldots$ & $\ldots$ & $\ldots$ & $\ldots$ & $\ldots$ & $\ldots$ \\
118 & 4 & 1 & 2 & 4 & 2 & 1355.1 & 147.55 & 7.6764 & 78.32 & 82.73 \\
119 & 3 & 3 & 1 & 4 & 1 & 1178.63 & 165.7 & 7.5893 & 71.51 & 97.65 \\
120 & 4 & 2 & 3 & 3 & 1 & 891.23 & 143.77 & 7.8308 & 75.67 & 98.07 \\
\hline
\end{tabular}

$$
\begin{aligned}
R^{2} & =1-\frac{\sum_{i=1}^{N}\left(y_{i}-\hat{y}_{i}\right)^{2}}{\sum_{i=1}^{N}\left(y_{i}-\bar{y}\right)^{2}}, \\
\operatorname{RMAE} & =\frac{\max \left\{\left|y_{1}-\hat{y}_{1}\right|, \ldots,\left|y_{N}-\bar{y}_{N}\right|\right\}}{\sum_{i=1}^{N}\left|y_{i}-\bar{y}\right| / N}, \\
\operatorname{RMSE} & =\sqrt{\frac{1}{N} \sum_{i=1}^{N}\left(y_{i}-\hat{y}_{i}\right)^{2},}
\end{aligned}
$$

where $\bar{y}$ is the mean response value of test points, $\hat{y}_{i}$ is the predicted response value and $y_{i}$ is the real test response value and $N$ is the number of test samples. The ideal surrogate model is supposed to meet the requirements that $R^{2}>0.9$, RMAE $<0.3$, and RMSE $<0.1$. After evaluating the Kriging surrogate model in I-sight software, it was obtained that all the values of $R^{2}$, RMAE, and RMSE meet the requirements, which indicates the Kriging model in this paper has high accuracy and reliability.

4.3. Implement of Adaptive Genetic Algorithm. The adaptive genetic algorithm is employed in the optimization problem 


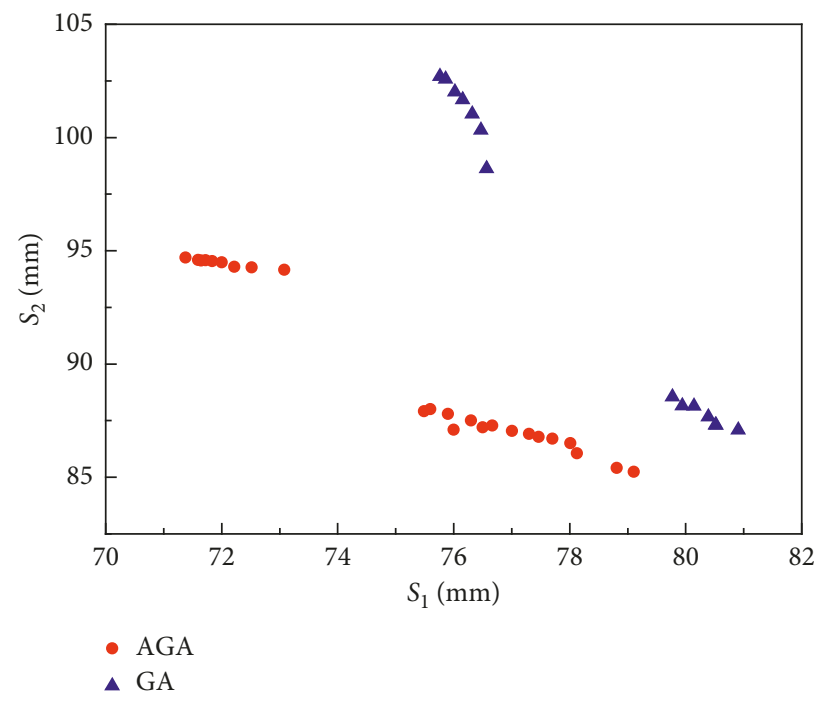

Figure 10: Pareto-optimal fronts of AGA and GA.

TABLE 4: Comparison of optimal solutions results.

\begin{tabular}{|c|c|c|c|c|c|}
\hline & $\begin{array}{c}\text { Initial aluminum } \\
\text { model }\end{array}$ & $\begin{array}{l}\text { GA-optimized } \\
\text { model }\end{array}$ & $\begin{array}{l}\text { AGA-optimized } \\
\text { model }\end{array}$ & $\begin{array}{c}\text { Compared to GA } \\
(\%)\end{array}$ & $\begin{array}{c}\text { Compared to initial } \\
\text { model }\end{array}$ \\
\hline $\bar{F}$ & $1006.920 \mathrm{~N}$ & $984.457 \mathrm{~N}$ & $906.591 \mathrm{~N}$ & -7.49 & -9.96 \\
\hline$L$ & $240.583 \mathrm{~mm}$ & $231.896 \mathrm{~mm}$ & $225.178 \mathrm{~mm}$ & -2.98 & -6.40 \\
\hline$Q$ & $7.239 \mathrm{KJ}$ & $7.741 \mathrm{~kJ}$ & $7.802 \mathrm{KJ}$ & 0.78 & 7.78 \\
\hline$S_{1}$ & $87.625 \mathrm{~mm}$ & $80.5465 \mathrm{~mm}$ & $75.490 \mathrm{~mm}$ & -6.70 & -13.85 \\
\hline$S_{2}$ & $98.566 \mathrm{~mm}$ & $88.363 \mathrm{~mm}$ & $87.911 \mathrm{~mm}$ & -0.51 & -10.81 \\
\hline$m$ & $3.790 \mathrm{~kg}$ & $2.153 \mathrm{~kg}$ & $2.153 \mathrm{Kg}$ & 0 & -43.19 \\
\hline $\begin{array}{l}\text { Design } \\
\text { variables }\end{array}$ & - & {$[90 / 45 / 90 / 45 /-45]$} & {$[90 / 90 / 45 /-45 / 45]$} & - & - \\
\hline
\end{tabular}

mentioned in Section 4.2. The stacking angles $0^{\circ},-45^{\circ}, 45^{\circ}$, and $90^{\circ}$ of each layer in CFRP are the genes, and they are encoded as $1,2,3$, and 4 . The stacking angle sequence $\left[x_{1} / x_{2} /\right.$ $\left.x_{3} / x_{4} / x_{5}\right]$ is the chromosomes. The Kriging surrogate models of $S_{1}$ and $S_{2}$ are the fitness functions while the Kriging surrogate models of $F, L$, and $Q$ are the constraint functions. The values of $P_{\mathrm{c}}$ and $P_{\mathrm{m}}$ are 1 and 0.5 for GA, and the values of $P_{\mathrm{c} 1}, P_{\mathrm{c} 2}, P_{\mathrm{m} 1}$, and $P_{\mathrm{m} 2}$ are $1,0.5,0.5$, and 0.01 , respectively, for AGA. To compare the optimal result between AGA and GA, the population size is set as 20 and maximum iteration is 2000 in both GA and AGA.

In terms of AGA, 24 Pareto solutions are obtained and 14 Pareto solutions are obtained using GA. The Paretooptimal fronts of AGA and GA are shown as Figure 10. In practical engineering requirement of crashworthiness, the upward displacement automotive steering column $S_{1}$ is as important as the rearward displacement automotive steering column $S_{2}$. Therefore, in this paper, the Pareto solution that has the minimum sum of $S_{1}$ and $S_{2}$ is selected as the optimal solution. Then, the optimal solutions of AGA and GA and the comparison to the initial aluminum model are shown in Table 4.

It can be concluded from Figure 10 that a more widespread and even distribution nondominated solution set is obtained by AGA. Both the number and the distributivity of Pareto solutions of AGA are better than those of GA. And the results also indicate that the crashworthiness indicators of the AGA-optimized bumper have slightly improvement than those of GA.

4.4. Verification of the Results to FE Model. To verify the optimal result of AGA in practical application, the best stacking angle consequence is applied in the FE model and then calculated in Ls-Dyna. The whole process of collision can be considered as the conversion of kinetic energy to internal energy, and the $\mathrm{C}$ curve of total energy basically maintains a horizontal shape, which represents that the total energy satisfies energy conservation. The maximum of the hourglass energy and slip energy should be less than $5 \%$ of the maximum kinetic energy, which means that they are within the acceptable range, which is depicted in Figure 11. It is a necessary precondition of collision simulation, and the optimized FE model meets the requirements. And the optimal results of the Kriging surrogate model are compared to the simulation results by FEA. The accuracy of surrogate model is shown in Table 5.

It can be concluded from the above results that the Kriging surrogate model is of high accuracy and the optimization algorithm is effective. And the comparison of crashworthiness performance in Ls-Dyna is shown in Figure 12. 


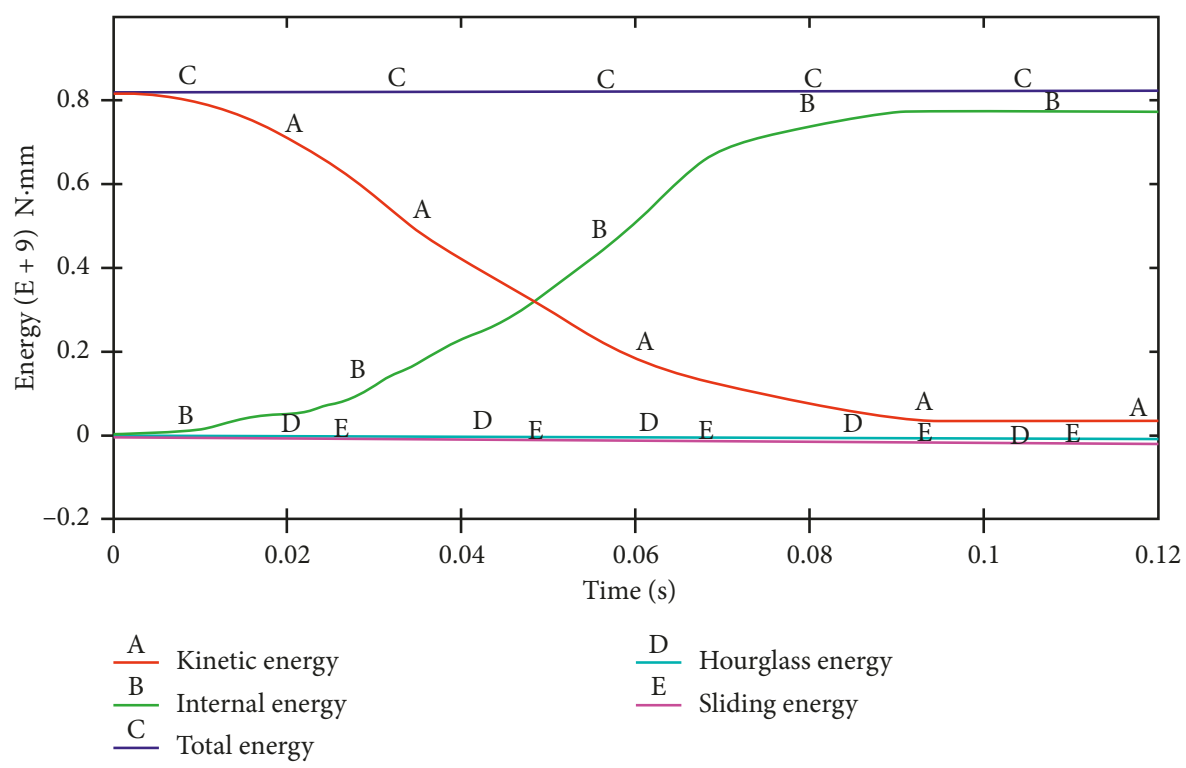

FIGURE 11: Energy change curve.

TABLe 5: Accuracy assessment of the Kriging surrogate model.

\begin{tabular}{lccc}
\hline Objective & FE model & Kriging model & Accuracy error (\%) \\
\hline$F$ & $908.403 \mathrm{~N}$ & $906.591 \mathrm{~N}$ & -0.12 \\
$L$ & $240.583 \mathrm{~mm}$ & $238.799 \mathrm{~mm}$ & -0.74 \\
$Q$ & $7.396 \mathrm{~kJ}$ & $7.802 \mathrm{~kJ}$ & 4.66 \\
$S_{1}$ & $74.647 \mathrm{~mm}$ & $75.490 \mathrm{~mm}$ & 1.13 \\
$S_{2}$ & $85.997 \mathrm{~mm}$ & $87.911 \mathrm{~mm}$ & 2.23 \\
\hline
\end{tabular}

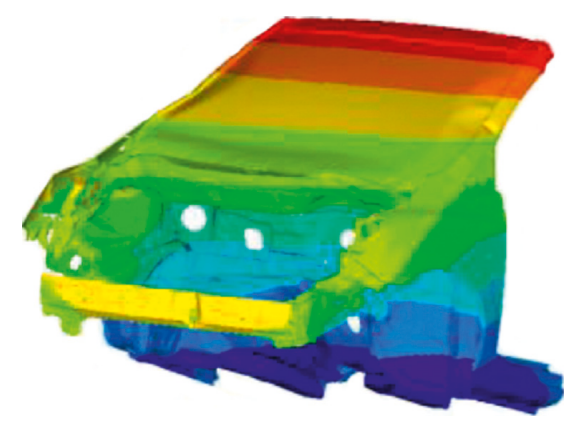

(a)

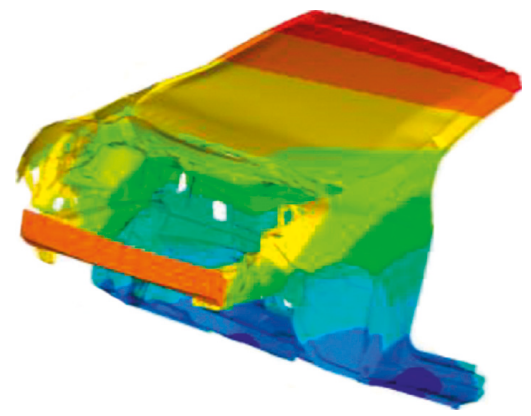

(b)

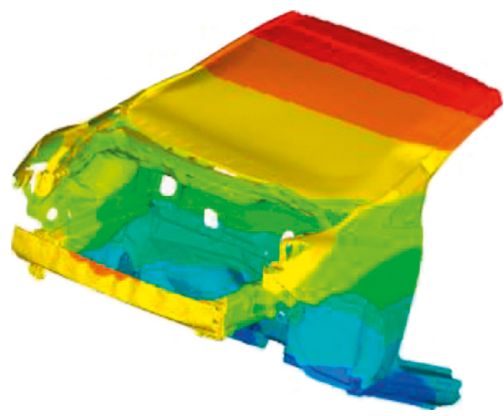

(c)

FIGURe 12: Comparison of crashworthiness performance in Ls-Dyna. (a) Initial aluminum model. (b) Model optimized by GA. (c) Model optimized by AGA.

\section{Conclusion}

In this study, a novel multiobjective optimization method considering the adaptive genetic algorithm and Kriging surrogate model is proposed for improving crashworthiness and reducing weight of the automotive bumper. The CFRP material is employed in the bumper beam instead of aluminum, and the optimal stacking angle sequence of each layer in CFRP is obtained by AGA. The following conclusion can be summarized:

(1) Compared with the genetic algorithm, the adaptive genetic algorithm proposed in this paper has higher convergence speed and stronger ability to search global optimal solutions. And applying them to the optimization problem in crashworthiness, the comparison results indicate the crashworthiness of the CFRP bumper optimized by AGA is better than that of GA.

(2) After the use of CFRP material in the bumper beam and optimization by AGA, the new bumper achieves 43.19\% weight reduction and exhibits better crashworthiness, compared to the initial aluminum bumper.

Furthermore, better optimization algorithm and more design variables of material will be considered into the research of the optimization of automotive bumper in the future. 


\section{Data Availability}

No data were used to support this study.

\section{Disclosure}

The views expressed in this paper are those of the authors and do not necessarily reflect the official views of affiliations.

\section{Conflicts of Interest}

The authors declare that they have no conflicts of interest.

\section{Acknowledgments}

This work was supported by the research fund of the Shanghai Automotive Industry Technology Development Foundation (1744), National Natural Science Foundation of China (Grant no. 51809168), and Young Teacher Initiation Program of Shanghai Jiao Tong University (17X100040060).

\section{References}

[1] G. Sun, J. Tian, T. Liu, X. Yan, and X. Huang, "Crashworthiness optimization of automotive parts with tailor rolled blank," Engineering Structures, vol. 169, pp. 201-215, 2018.

[2] K. K. Dama, V. Suresh Babu, and R. N. Rao, "State of the art on automotive lightweight body-in-white design," Materials Today: Proceedings, vol. 5, no. 10, pp. 20966-20971, 2018.

[3] X. Chen, X. Wang, Z. Qiu, L. Wang, X. Li, and Q. Shi, “A novel reliability-based two-level optimization method for composite laminated structures," Composite Structures, vol. 192, pp. 336-346, 2018.

[4] D.-H. Kim, K.-H. Jung, D.-J. Kim et al., "Improving pedestrian safety via the optimization of composite hood structures for automobiles based on the equivalent static load method," Composite Structures, vol. 176, pp. 780-789, 2017.

[5] P. Alam, D. Mamalis, C. Robert, C. Floreani, and C. M. Ó Brádaigh, "The fatigue of carbon fibre reinforced plastics-a review," Composites Part B: Engineering, vol. 166, pp. 555$579,2019$.

[6] J. H. S. Almeida, M. Ribeiro, V. Tita, and S. Amico, "Stacking sequence optimization in composite tubes under internal pressure based on genetic algorithm accounting for progressive damage," Composite Structures, vol. 178, pp. 20-26, 2017.

[7] J. H. S. Almeida, L. Bittrich, T. Nomura, and A. Spickenheuer, "Cross-section optimization of topologically-optimized variable-axial anisotropic composite structures," Composite Structures, vol. 225, Article ID 111150, 2019.

[8] G. Sun, Z. Wang, H. Yu, Z. Gong, and Q. Li, "Experimental and numerical investigation into the crashworthiness of metal-foam-composite hybrid structures," Composite Structures, vol. 209, pp. 535-547, 2019.

[9] L. Kiran, S. Kakkeri, and S. Deshpande, "Proposal of hybrid composite material for light commercial vehicle chassis," Materials Today: Proceedings, vol. 5, no. 11, pp. 24258-24267, 2018.

[10] G. Belingardi, A. T. Beyene, E. G. Koricho, and B. Martorana, "Alternative lightweight materials and component manufacturing technologies for vehicle frontal bumper beam," Composite Structures, vol. 120, pp. 483-495, 2015.
[11] Z. Liu, J. Lu, and P. Zhu, "Lightweight design of automotive composite bumper system using modified particle swarm optimizer," Composite Structures, vol. 140, pp. 630-643, 2016.

[12] M. M. Davoodi, S. M. Sapuan, D. Ahmad, A. Ali, A. Khalina, and M. Jonoobi, "Mechanical properties of hybrid kenaf/glass reinforced epoxy composite for passenger car bumper beam," Materials \& Design, vol. 31, no. 10, pp. 4927-4932, 2010.

[13] D.-H. Kim, D.-H. Choi, and H.-S. Kim, "Design optimization of a carbon fiber reinforced composite automotive lower arm," Composites Part B: Engineering, vol. 58, no. 8, pp. 400-407, 2014.

[14] X. An, Y. Gao, J. Fang, G. Sun, and Q. Li, "Crashworthiness design for foam-filled thin-walled structures with functionally lateral graded thickness sheets," Thin-Walled Structures, vol. 91, pp. 63-71, 2015.

[15] M. Abbasi, A. Ghafari-Nazari, S. Reddy, and M. Fard, "A new approach for optimizing automotive crashworthiness: concurrent usage of ANFIS and Taguchi method," Structural and Multidisciplinary Optimization, vol. 49, no. 3, pp. 485-499, 2014.

[16] F. L. Gao, Y. C. Bai, C. Lin, and I. Y. Kim, “A time-space Kriging-based sequential metamodeling approach for multiobjective crashworthiness optimization," Applied Mathematical Modelling, vol. 69, pp. 378-404, 2019.

[17] L. Xiaojiang, D. Zhou, G. Sun, and W. Gu, "Crashworthiness and lightweight design of mule-car body based on multiobjective reliability optimization," Automotive Engineering, vol. 40, no. 7, 2018.

[18] J. Fang, G. Sun, N. Qiu, N. H. Kim, and Q. Li, "On design optimization for structural crashworthiness and its state of the art," Structural and Multidisciplinary Optimization, vol. 55, no. 3, pp. 1091-1119, 2017.

[19] J. Fang, N. Qiu, X. An, F. Xiong, G. Sun, and Q. Li, "Crashworthiness design of a steel-aluminum hybrid rail using multi-response objective-oriented sequential optimization," Advances in Engineering Software, vol. 112, pp. 192199, 2017.

[20] S. Pirmohammad and S. Esmaeili Marzdashti, "Crashworthiness optimization of combined straight-tapered tubes using genetic algorithm and neural networks," Thin-Walled Structures, vol. 127, pp. 318-332, 2018.

[21] G. Sun, T. Liu, J. Fang, G. P. Steven, and Q. Li, "Configurational optimization of multi-cell topologies for multiple oblique loads," Structural and Multidisciplinary Optimization, vol. 57, no. 2, pp. 469-488, 2018.

[22] Y. Song and C. Teng, "Optimal decision model and improved genetic algorithm for disposition of hierarchical facilities under hybrid service availability," Computers \& Industrial Engineering, vol. 130, pp. 420-429, 2019.

[23] E. Shojaedini, M. Majd, and R. Safabakhsh, "Novel adaptive genetic algorithm sample consensus," Applied Soft Computing, vol. 77, pp. 635-642, 2017.

[24] L. R. da Silveira, R. Tanscheit, and M. M. B. R. Vellasco, "Quantum inspired evolutionary algorithm for ordering problems," Expert Systems with Applications, vol. 67, pp. 7183, 2017.

[25] C. Yang, Q. Qian, F. Wang et al., "Application of improved adaptive genetic algorithm in function optimization," $A p$ plication Research of Computers, vol. 35, no. 4, pp. 1042-1045, 2018.

[26] M. Srinivas and L. M. Patnaik, "Adaptive probabilities of crossover and mutation in genetic algorithms," IEEE Transactions on Systems, Man, and Cybernetics, vol. 24, no. 4, pp. 656-667, 1994. 
[27] M. J. Mahmoodabadi and A. R. Nemati, "A novel adaptive genetic algorithm for global optimization of mathematical test functions and real-world problems," Engineering Science and Technology, an International Journal, vol. 19, no. 4, pp. 2002-2021, 2016.

[28] Z. Dong, H. Jia, and M. Liu, "An adaptive multiobjective genetic algorithm with fuzzy c-means for automatic data clustering," Mathematical Problems in Engineering, vol. 2018, Article ID 6123874, 13 pages, 2018.

[29] H. M. Pandey, A. Chaudhary, and D. Mehrotra, "A comparative review of approaches to prevent premature convergence in GA," Applied Soft Computing, vol. 24, pp. 1047-1077, 2014

[30] Y.-W. Shang and Y.-H. Qiu, "A note on the extended Rosenbrock function,” Evolutionary Computation, vol. 14, no. 1, pp. 119-126, 2006.

[31] K. S. Gan, P. Anthony, and J. Teo, "The effect of varying the crossover rate in the evolution of bidding strategies," in Proceedings of the 4th International IASTED Conference on Advances in Computer Science and Technology, pp. 162-167, Langkawi, Malaysia, April 2008.

[32] L. Hai-Jiang, Z. Xia, and X. Li-Fang, "Collision simulation analysis of 7075 aluminum alloy car bumper based on LSDYNA," Journal of Machine Design, vol. 28, no. 2, pp. 18-23, 2011.

[33] China Automotive Technology and Research Center, "CNCAP management regulation,” 2018, http://www.c-ncap. org/cncap/pjgz.

[34] G. Belingardi, B. Koricho, and B. Martorana, "Implementation of composite and recyclable thermoplastic materials for automotive bumper subsystem," International Journal of Automotive Composites, vol. 1, no. 1, p. 67, 2014.

[35] J. O. Hallquist, LS-DYNA Theory Manual, Livermore Software Technology Corporation, Livermore, CA, USA, 2006.

[36] J. H. S. Almeida Jr, S. D. B. Souza, E. C. Botelho, and S. C. Amico, "Carbon fiber-reinforced epoxy filament-wound composite laminates exposed to hygrothermal conditioning," Journal of Materials Science, vol. 51, no. 9, pp. 4697-4708, 2016.

[37] H. A. Deveci and H. S. Artem, "Optimum design of fatigueresistant composite laminates using hybrid algorithm," Composite Structures, vol. 168, pp. 178-188, 2017.

[38] C. Zhang, P. Zhu, Q. Feng, J. He, and Q. Zhou, "Optimization study on carbon fiber reinforced plastic vehicle fender," Automotive Engineering, vol. 5, no. 5, pp. 367-374, 2015, in Chinese.

[39] O. Montagnier and C. Hochard, "Optimisation of hybrid high-modulus/high-strength carbon fiber reinforced plastic composite drive shafts," Materials And Design, vol. 46, pp. 88-100, 2013.

[40] C.-C. Liang and H.-W. Chen, "Optimum design of fiberreinforced composite cylindrical skirts for solid rocket cases subjected to buckling and overstressing constraints," Composites Part B: Engineering, vol. 34, no. 3, pp. 273-284, 2003.

[41] J. Fang, Y. Gao, G. Sun, C. Xu, and Q. Li, "Fatigue optimization with combined ensembles of surrogate modeling for a truck cab," Journal of Mechanical Science and Technology, vol. 28, no. 11, pp. 4641-4649, 2014.

[42] S. Guangyong, T. Wang, X. Tian, and H. Kang, "Crashworthiness design of high strength steel tailor-welded blank (TWB) based on multi-objective discrete optimization method," China Sciencepaper, vol. 11, no. 4, pp. 438-448, 2016.

[43] E. Raponi, M. Bujny, M. Olhofer, N. Aulig, S. Boria, and F. Duddeck, "Kriging-assisted topology optimization of crash structures," Computer Methods in Applied Mechanics and Engineering, vol. 348, pp. 730-752, 2019.

[44] Y. Yu-Jie, W. Zong-Yan, and Z. Zi-Jian, "Lightweight study of bridge girder based on DOE and wolves algorithm," $M a$ chinery Design \& Manufacturing, vol. 333, no. 11, pp. 186-189, 2018.

[45] K. Kang, C. Qin, B. Lee, and I. Lee, "Modified screening-based Kriging method with cross validation and application to engineering design," Applied Mathematical Modelling, vol. 70, pp. 626-642, 2019. 


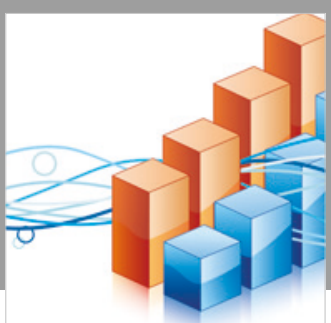

Advances in

Operations Research

\section{-n-m}
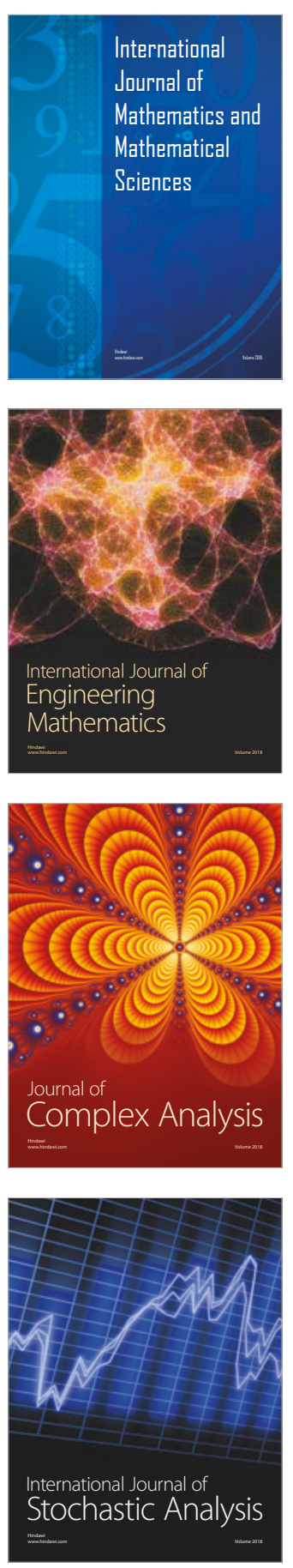
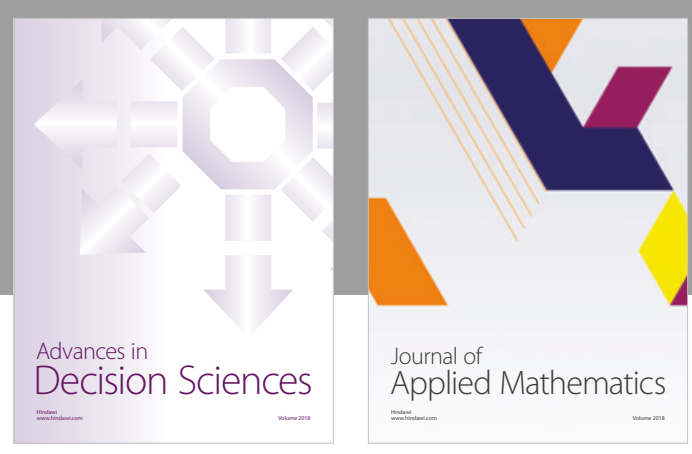

Journal of

Applied Mathematics
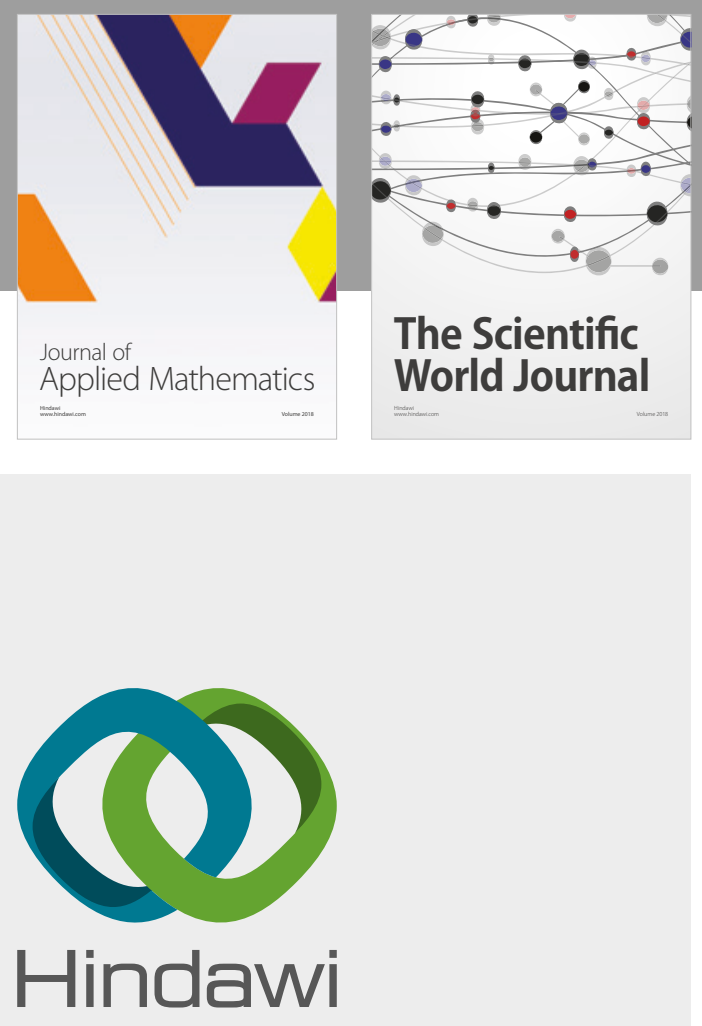

Submit your manuscripts at

www.hindawi.com

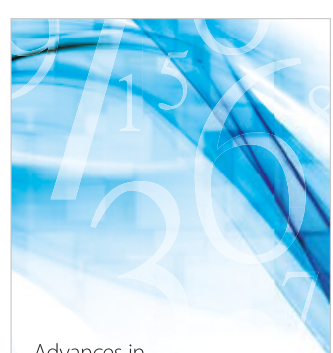

Advances in
Numerical Analysis
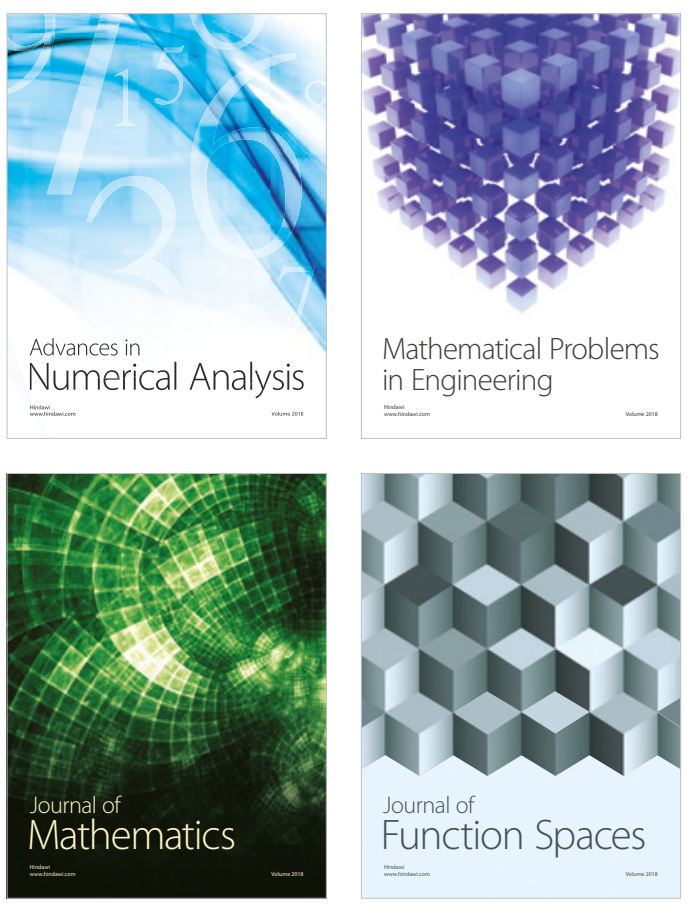

Mathematical Problems in Engineering

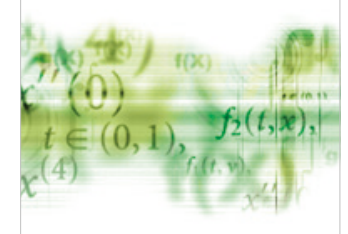

International Journal of

Differential Equations

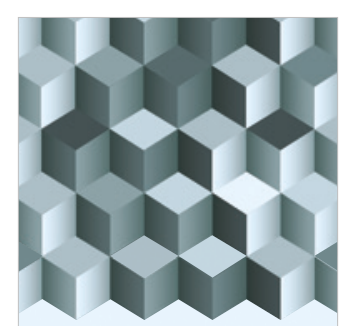

Journal of

Function Spaces
The Scientific

World Journal

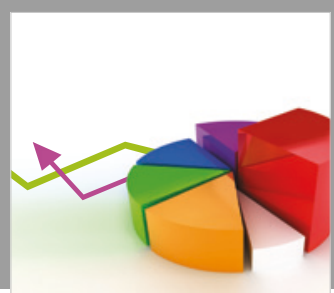

Journal of

Probability and Statistics
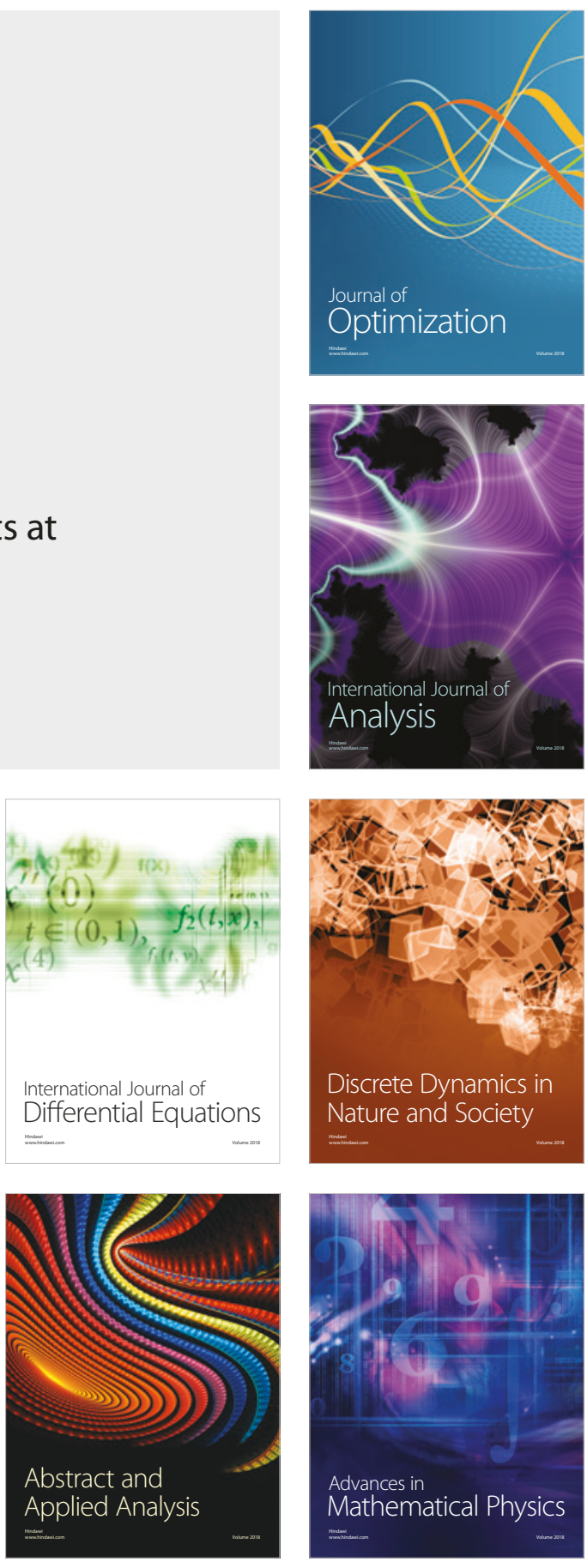